\title{
Do Institutions Determine Economic Geography? Evidence from the Concentration of Foreign Suppliers
}

by

\author{
Fariha Kamal \\ U.S. Cens us Bureau
}

As ha Sundaram

University of Auckland

\section{CES 19-05 February, 2019}

The research program of the Center for Economic Studies (CES) produces a wide range of economic analyses to improve the statistical programs of the U.S. Census Bureau. Many of these analyses take the form of CES research papers. The papers have not undergone the review accorded Census Bureau publications and no endorsement should be inferred. Any opinions and conclusions expressed herein are those of the author(s) and do not necessarily represent the views of the U.S. Census Bureau. All results have been reviewed to ensure that no confidential information is disclosed. Republication in whole or part must be cleared with the authors.

To obtain information about the series, see www.census.gov/ces or contact Christopher Goetz, Editor, Discussion Papers, U.S. Census Bureau, Center for Economic Studies 5K028B, 4600 Silver Hill Road, Washington, DC 20233, CES.Working.Papers@ @ensus.gov. To subscribe to the series, please click here. 


\begin{abstract}
Do institutions shape the geographic concentration of industrial activity? We explore this question in an international trade setting by examining the relationship between country-level institutions and patterns of spatial concentration of global sourcing. A priori, weak institutions could be associated with either dispersed or concentrated sourcing. We exploit location and transaction data on imports by U.S. firms and adapt the Ellison and Glaeser (1997) index to construct a productcountry-specific measure of supplier concentration for U.S. importers. Results show that U.S. importers source in a more spatially concentrated manner from countries with weaker contract enforcement. We find support for the idea that, where formal contract enforcement is weak, local supplier networks compensate by sharing information to facilitate matching and transactions.
\end{abstract}

Keyword: buyer-seller match, global sourcing, contract enforcement, institutions, spillovers, trade

JEL Classification: F1, F6, F14, R12

\footnotetext{
* Any opinions and conclusions expres sed herein are those of the authors and do not necessarily represent the views of the U.S. Census Bureau. All results have been reviewed to ensure that no confidential information is disclosed. Kamal: Corresponding author.
} 


\section{Introduction}

Do institutions shape the geographic concentration of industrial activity? While we know that patterns of geographic concentration vary across countries, we know little about their determinants. In this paper, we examine how variation in the quality of institutions shapes the spatial organization of economic activity across countries by influencing sourcing patterns in international trade. Specifically, we ask whether U.S. importers source in a more spatially dispersed or concentrated manner from countries with weaker contract enforcement regimes.

The relationship between institutions and spatial patterns of global sourcing strategies is, ex ante, ambiguous. On the one hand, decentralization forces may result in more dispersed patterns of global sourcing under weak institutions. For example, countries with weak institutional environments might be more susceptible to outbreak of violence and conflict or suffer from weak state capacity to manage recovery from catastrophic events like natural disasters. Firms sourcing from such environments may prefer to diversify their suppliers across regions to mitigate the risk that supply is cut off for a period of time after an adverse event (Cole, Elliott, Okubo, Strobl, 2017; Henriet and Tabourier, 2012).

On the other hand, weaker institutions may result in higher spatial concentration in global sourcing patterns. First, importing firms sourcing from a country with a weaker contract enforcement regime may be more likely to rely on their network of suppliers when establishing new supplier links in a city. A poor contracting environment can result in high transaction costs and frequent losses for firms from hold-ups or reneging by either party in a business transaction. Where the legal system cannot effectively uphold contracts, informal institutions can substitute for them by providing information on the reputation and reliability of suppliers or by sanctioning default, thereby mitigating some of the costs weak institutions impose (Greif, 1993; McMillan and Woodruff, 1999). Second, institutionally weaker countries may be characterized by primate cities where economic activity tends to concentrate (Ades and Glaeser, 1995). Finally, trade with 
institutionally weak countries might be routed disproportionately through intermediaries, who might operate primarily from port cities or urban centers (Ahn, Khandelwal, Wei, 2011).

We empirically evaluate the net impact of institutional quality on supplier concentration using the universe of confidential U.S. merchandise customs data. We observe import transactions of a product by a U.S. importer from distinct suppliers located across cities within a country. We construct an index of supplier concentration for each U.S. importer specific to a product and country. We adapt the index of spatial concentration in Ellison and Glaeser (1997) to measure supplier concentration, henceforth EG index, which varies at the importer-product-country level. In the context of our study, the EG index measures the concentration of suppliers to a U.S. importer above the overall concentration of exporters to the U.S., the latter capturing exporters' tendencies to agglomerate in space. Thus, our measure of supplier spatial concentration isolates importer-level deviations from overall exporter concentration within a product-country pair.

We find that U.S. importers tend to source in a more spatially concentrated manner in countries with weaker institutions. Our results indicate that a decrease of ten in the number of procedures required to legally enforce a contract (about 28\% of the mean across countries) is associated with a decrease in the EG supplier concentration index of 0.5. We also find that a decrease of 100 in the number of days required to legally enforce a contract (about $21 \%$ of the mean across countries) is associated with a decrease in the EG supplier concentration index of 0.1. These results are robust to including a battery of control variables, an instrumental variables estimation strategy to account for the endogeneity of institutions, using alternate measures of institutions and the spatial concentration of sourcing, and utilizing samples in different years.

Next, we explore the mechanisms through which weaker institutional quality is associated with greater spatial concentration of sourcing by U.S. importers. We find strong support that the negative relationship between contract enforcement and the spatial concentration of sourcing persists even after we exclude primate cities and suppliers that are potential trade intermediaries 
from our analysis. We also find evidence consistent with the idea that costs associated with weak institutions may be mitigated through reliance on local supplier networks.

This research makes two key contributions to the urban agglomeration literature. First, although prior studies have established differences in patterns of spatial concentration of economic activity across countries, we know little about their determinants (Chauvin, Glaeser, Ma, Tobio, 2017). To the best of our knowledge, our paper is one of the first to propose institutional quality as one such determinant, by focusing on its role in shaping sourcing patterns in international trade. Second, we establish patterns in the geographic concentration of sourcing by U.S. importers consistent with the idea that local business networks facilitate spillovers in information (Fernand es and Tang, 2014; Kamal and Sundaram, 2016; Koenig, 2009; Koenig, Mayneris, Poncet, 2010; Lovely, Rosenthal, Sharma, 2005). ${ }^{3}$ Our finding of foreign buyers' propensity to match with domestic suppliers in a spatially concentrated manner suggest that localization economies for production may arise not only via input sharing, labor market pooling, and knowledge spillovers but also because clusters of domestic suppliers may be able to attract more foreign buyers than suppliers acting individually.

This paper also contributes to the empirical international trade literature that demonstrates the importance of institutional quality in determining trade patterns, including propensity to import differentiated intermediate inputs (Bernard, Jensen, Redding, Schott; 2010), export dynamics (Araujo, Mion, Ornelas; 2016), and comparative advantage (Antràs and Helpman, 2008; Levchenko, 2007; Nunn, 2007; Nunn and Trefler, 2014). Complementing this rich body of work, we highlight an additional role for institutions in influencing international trade - spatial patterns in global sourcing.

\footnotetext{
${ }^{3}$ The information flow within an importer's supplier network is considered to be "spillovers" since firms in our conceptual framework do not internalize these externalities.
} 
The next section outlines our conceptual framework followed by Section 3, where we develop our empirical specifications. Section 4 provides a description of the data sources and summary statistics followed by our results in Section 5. The final section concludes.

\section{Conceptual Framework}

In this section, we sketch the intuition guiding our hypothesis on the relationship between institutional quality and spatial concentration of sourcing. The direction of this relationship is shaped by two opposing forces. On the one hand, global supply chains may be particularly vulnerable to disruption from catastrophic events like conflict or natural disasters in countries with weak institutions. Buyers operating in such environments may wish to plan proactively to mitigate risk by diversifying suppliers across locations (Haraguchi and Lall, 2015; Knemeyer, Zinn, Eroglu, 2009). On the other hand, firms may choose to source in a more concentrated manner in countries with weak institutions. This is likely if they source predominantly from primate cities or through intermediaries in such countries. Moreover, supplier networks may mitigate costs associated with contractual frictions, a channel that we examine specifically in this study.

Suppose that firms seeking to source from abroad (import) face efficiency losses associated with weak institutions that reduce profitability (as in Antràs, 2015). When contracting institutions are not well developed in the source country, or the rule of law is weak, firms have to incur costs to mitigate risks against hold-up problems or expropriation. Consider a firm that already sources from a supplier located in a city in a source country and is looking to source from an additional supplier. ${ }^{4}$ Sourcing from a new city involves additional city-specific fixed costs, like searching for a reliable input supplier and establishing transport links to the new city. Firms trade off incurring these city-specific fixed costs with the expected gain from accessing a lower-cost supplier in a new city. Finding a new supplier in a new city exposes the firm to risks associated with hold-up or expropriation.

\footnotetext{
${ }^{4}$ Our empirical analysis is conditional on an importer sourcing from a particular country and we only consider U.S. firms sourding from multiple suppliers in a given sou rce country.
} 
We posit that the costs to manage these risks are higher in countries with weak institutional environments. Sourcing from a new supplier in the same city, on the other hand, may mitigate some of the costs associated with weak institutions. Firms may have access to better information within the same city through local business networks, either about individual input suppliers, their reputation and reliability, or about doing business in the local city environment. In an environment where institutions are weak, the gains from finding a lower-cost supplier in a new city would be more substantially eroded by costs involved in sourcing from a new city. Thus, within this framework, firms are more likely to source in a spatially concentrated manner from partner countries with weak institutional environments. ${ }^{5}$

\section{Empirical Specification}

\subsection{Institutional Quality and Supplier Concentration}

To measure a U.S. importer's supplier concentration in a source country, we adopt the EG index following Ellison and Glaeser (1997). A key contribution of our study is the application of this index to capture the spatial concentration patterns in foreign sourcing. The EG index is widely used to measure geographic concentration of economic activity. It measures agglomeration of economic activity relative to what one would observe if firm location choice were random. In our application, the index measures a U.S. importer's geographic concentration of sourcing relative to the concentration of all suppliers to the U.S. from the same country. This adaptation of the EG index isolates the concentration of suppliers to a U.S. importer over and above the concentration implied by the agglomeration of exporting firms located within an industry and city in the source country.

As emphasized in the agglomeration literature that studies location choices of firms, domestic firms, and exporters in particular, have a tendency to agglomerate (Glaeser and Gottlieb,

\footnotetext{
${ }^{5}$ We outline a simple model in Section A 3 of the Appendix motivating the relationship of interest between probability of sourcing from suppliers in a given city and institutional quality in the source country.
} 
2009; Henderson, 2003; Koenig, 2009; Puga, 2010; Rosenthal and Strange, 2004). Our application of the EG index captures this tendency of suppliers to locate in a concentrated manner by accounting for the overall concentration of all suppliers to the U.S. within an industry and city. ${ }^{6}$

We construct $E G_{m c p}$, an index of supplier concentration, for a U.S. importer $m$, sourcing product $p$ from city $j$ in country $c$, as follows:

$$
E G_{m c p}=G-\left(1-\sum_{j} x_{j c p}^{2}\right) H /\left(1-\sum_{j} x_{j c p}^{2}\right)(1-H)
$$

where $p$ is a four-digit HS product code. ${ }^{7}$ The spatial Gini coefficient (also used independently to measure geographic concentration as in Audretsch and Feldman (1996)) is given by $G \equiv$ $\sum_{j=1}^{N_{c p}}\left(s_{m j c p}-x_{j c p}\right)^{2}$. Here, $s_{m j c p} \equiv \frac{v^{\text {alue }} m j c p}{\text { value }_{m c p}}$ represents the share of imports of product $p$ that importer $m$ buys from city $j$ in the total value of imports of product $p$ bought by importer $m$ from country $c . \quad x_{j c p} \equiv \frac{\text { value }_{j c p}}{\text { value }_{c p}}$ represents the total value of U.S. imports of product $p$ from city $j$ as a share in total U.S. imports of product $p$ from country $c . N_{c p}$ refers to the total number of cities supplying product $p$. The product-level spatial Gini coefficient measures the concentration of sourcing by a U.S. importer above the concentration of exporters to the U.S.

If the U.S. importer sources from a small number of suppliers from the country, we would observe a high value of the spatial Gini (indicating concentration) simply because a small number of suppliers are less likely to be spread across many cities. To account for this, Ellison and Glaeser (1997) propose adjusting the spatial Gini with a Herfindahl index, which we adapt to our setting

\footnotetext{
${ }^{6}$ Although we cannot separately measure total domestic activity within an industry-city in a source country due to data constraints, we believe that our measure of concentration by exporters in a source country selling to the U.S. correlates very highly with overall domesticactivity within that industry-city. It thus controls for the concentration of economicactivity in the source country that may arise from local agglom eration economies. In addition, o ur em pirical specification controls for the concentration of economic activity in a country using night-lights data (Henderson, Storeygard, Weil, 2012). Finally, we exdude transactions in resource-intensive products, since these may be driven by natural advantage - an alternate source of agglom eration economies.

7 A four-digit HS code is roughly comparable to a four-digit NAICS industry. U.S. import transactions are collected at the ten-digit HS level. The choice of four-digit HS product is motivated by the desire to measure concentration at a fairly disaggregated level while still allowing for enough observations within a country-product space to meet Census Bureau disdosure requirements.
} 
as $H \equiv \sum_{k=1}^{S_{m c p}}\left(z_{k m c p}\right)^{2}$ where $z_{k m c p} \equiv \frac{\text { value }_{k m c p}}{\text { value }_{m c p}}$ measures importer $m$ 's imports of product $p$ from each supplier, $k$, as a share of importer $m$ 's total imports of product $p$ from country $c . S_{m c p}$ is the total number of suppliers in country $c$ supplying product $p$ to importer $m .8$

Two important properties of the EG index, as defined in (3.1), make it suitable for testing our research question. First, the index allows us to succinctly capture patterns of sourcing by U.S. importers and is comparable across countries. Second, the index controls for concentration that may arise if U.S. importers source a larger share of imports from only a few suppliers and hence appear to source in a concentrated manner across cities. ${ }^{9}$ In a robustness exercise, we construct an alternate EG index using the count of suppliers instead of trade value and verify that our results remain qualitatively similar using this alternate index.

To explore the relationship between institutions and spatial concentration of sourcing, we estimate the following equation.

$E G_{m c p}=\alpha+\beta$ Institutions $_{c}+\gamma X_{c}+\theta X_{c p}+\delta_{m}+\vartheta_{p}+\epsilon_{m c p}$

Institutional quality in country $c$ is captured by Institutions ${ }_{c} ; X_{c}$ a set of country-specific control variables; and $X_{c p}$, a set of country-product specific control variables. Country-specific variables include information- and transport-infrastructure, GDP per capita, population, land area, common language with the U.S., and concentration of economic activity (measured with nightlights data). Country-product controls include the total number of suppliers and total number of cities selling product $p$ from country $c . \delta_{m}$ and $\vartheta_{p}$ refer to a set of importer and product fixedeffects, respectively. $\epsilon_{m c p}$ is an idiosyncratic error term. In all our tables, we report robust standard errors clustered at the country-level. A priori, the net impact of institutions on supplier concentration, and hence the expected sign of the estimated $\beta$ is ambiguous.

\footnotetext{
8 The Herfindahl index has no city component to it. The term $\left(1-\sum_{j} x_{j c p}^{2}\right)$, appears in the EG index following Ellison and Glaeser (1997). In the context of this study the expected value for $G$ is $\left[E G_{m c p}\left(1-\sum_{j} x_{j c p}^{2}\right)(1-H)\right]+$ $\left(1-\sum_{j} x_{j c p}^{2}\right) H$

${ }^{9}$ We cannot calculate the EG index for importers that source from a single supplier in a given product-country pair. Single-supplier im porter-product pairs are effectively exduded from our analysis sample.
} 
The empirical specification exploits cross-country variation in a U.S. importer's supplier concentration to identify the relationship of interest after accounting for unobserved importerand product-specific characteristics. A remaining concern is unobserved country-specific factors that may drive both institutional quality and sourcing concentration simultaneously.

\subsection{Identification}

We adopt an instrumental variables strategy to address potential simultaneity bias. We instrument for institutions with legal origins at the country-level following Nunn (2007). The idea exploited here is that the legal origin of a country affects institutional quality (given persistence in institutions) but drives contemporaneous economic outcomes only through the channel of institutions. We find that our result is robust to the instrumental variables strategy. We also confirm that our result is robust including a set of importer-product fixed effects to our baseline model to account for importer-product specific unobserved heterogeneity.

A key channel determining the relationship between institutions and the spatial concentration of sourcing highlighted in our conceptual framew ork is that in the absence of formal institutions, supplier networks may lower the costs of matching and transacting by acting as a source of information on the needs, reputation, and reliability of trading partners and sanctioning contract violations. Weak institutions thereby result in greater spatial concentration of sourcing. Although we are unable to test this idea directly, we estimate an extended version of our baseline specification that we detail below. ${ }^{10}$

The extended model that we estimate rests on two hypotheses. First, we hypothesize that losses for the importer from contract violations are likely to be exacerbated in industries that are more contract intensive, where a larger proportion of inputs are relationship-specific and not bought or sold in an exchange or reference priced (Nunn, 2007). Second, we hypothesize that supplier networks have a greater incentive to sanction default and contract violations in cities

\footnotetext{
${ }^{10}$ We thank an anonymous referee for this suggestion.
} 
where U.S. importers are heavily concentrated and hence have more bargaining power relative to local suppliers. We estimate the following specification,

$$
\begin{aligned}
E G_{m c p}= & \alpha+\beta_{1} \text { Institutions }_{c} * z_{m}+\beta_{2} \text { Institutions }_{c} * y_{m c p}+\beta_{3} \text { Institutions }_{c} * z_{m} * y_{m c p} \\
& +\theta X_{c p}+\eta_{c}+\delta_{m}+\vartheta_{p}+\epsilon_{m c p}
\end{aligned}
$$

where, $z_{m}$ captures contract intensity at the six-digit NAICS industry of the importer, defined as the proportion of inputs used in production that are neither bought or sold on an exchange nor referenced priced, obtained from Nunn (2007). ${ }^{11}$ A caveat is that the measure of contract intensity is available predominantly for the manufacturing sectors that results in a significant reduction in our sample size and a potential loss of power. We construct a measure of importer concentration as follows,

$y_{m c p}=\sum_{j=1}^{N_{c p}} s_{m j c p} H_{j c p}$,

where, $s_{m j c p} \equiv \frac{\text { value }_{m j c p}}{\text { value }_{m c p}}$ is defined as in (3.1) and represents the share of imports of product $p$ that importer $m$ buys from city $j$ in the total value of imports of product $p$ bought by importer $m$ from country $c . H_{j c p}$ is a Herfindahl index of U.S. importer concentration in product $p$, city $j$ of country $c . X_{c p}$ is a set of country-product specific control variables. The parameters $\eta_{c}, \delta_{m}$ and $\vartheta_{p}$ are country, importer and product fixed effects, respectively. We expect a negative coefficient on the interaction term between institutional quality and contract intensity $\left(\beta_{1}<0\right)$. This implies that the effect of institutional quality on spatial supplier concentration is more negative for importers in industries that are contract intensive and more so for importers sourcing from areas characterized by high concentration of U.S. importers $\left(\beta_{3}<0\right)$.

In a final extension, we introduce a squared term of the institutional quality measure in (3.2) to test whether the relationship between institutions and the concentration of sourcing is non-linear.

\footnotetext{
${ }^{11}$ The contract intensity measure is available at the six-digit NAICS level and accessed on January 13, 2018 at https://scholar.harvard.edu/nunn/pages/data-0.
} 


\section{Data}

We test our hypotheses using confidential U.S. firm-trade transactions linked data in conjunction with measures of institutional quality and additional country-level controls. Availability of firm-level import transactions data identifying both trading parties in the transaction permits construction of spatial sourcing concentration measures for an importer-product-country triad. Guided by our interest in understanding the role of institutions in shaping the patterns of spatial concentration of sourcing by U.S. importers from a country, we utilize measures of contract enforcement or the ease with which contracts can be legally enforced. Institutions change slowly over time such that measures of institutional quality derive most of its variation within a crosssection (Dell and Olken, 2017). We perform cross-sectional empirical analyses utilizing data from 2011..$^{12}$

\subsection{Firm-Trade Transactions Data}

We use U.S. merchandise import transactions in the Linked Firm Trade Transactions Database (LFTTD) maintained by the U.S. Census Bureau. The import transactions data contain an identifier for the U.S. importer and the foreign exporter. The foreign exporter or supplier is uniquely identified by the "Manufacturer ID" (MID) that is a required field on the form (Form 7501) U.S. importers must file with the U.S. Customs and Border Protection. ${ }^{13}$ The MID is an alphanumeric code constructed using a pre-specified algorithm with a maximum length of 15 characters. ${ }^{14}$ The last three characters in the MID designate the city where the manufacturer is located. We treat a distinct three-letter code as a unique city. We carry out robustness checks to address concerns that there may exist multiple cities within a country beginning with the same first three letters. ${ }^{15}$

\footnotetext{
122011 was the latest available year at the time we began our study. Also, motivating our choice is the extensive deaning of the foreign supplieridentifier variable in 2011 performed by Kamal and Monarch (2018).

13 See form https://www.dbp.gov/sites/default/files/assets/documents/2018-Feb/CBP\%20Form\%207501.pdf.

14 See Block 13 (pg. 7) for description of MID and Appendix 2 (pg. 30) for instructions on constructing MID at https://www.cbp.gov/sites/default/files/assets/documents/2016-

Sep $/$ CBP $\% 20$ Form $\% 207501$ Instructions $\% 20 \% 28$ Fixed $\% 20$ Links $\% 2009-07-2016 \% 29$.pdf.

15 Since we identify cities within a country using the three letter codes extracted from the MID, it is possible that for dities that begin with the same three letters, a single code may actually represent multiple cities and introduce
} 
We restrict the data in three main ways. First, we only employ arm's length transactions thereby excluding related-party transactions. ${ }^{16}$ Sourcing strategies from subsidiary or parent companies as compared to unaffiliated parties are governed by very different economic forces (Ramondo, Rappoport, Ruhl, 2016). Second, we exclude natural resource-intensive products whose production location is more likely to be governed by natural advantages. ${ }^{17}$ Finally, we exclude observations for countries in the sample that are associated with a single city, representing an insignificant share (less than $0.01 \%$ ) of the overall sample.

In our descriptive analyses, we construct indicators for importer size. We obtain information on firm employment and industry from the Longitudinal Business Database (LBD) that consists of data on all private, non-farm U.S. establishments in existence that have at least one paid employee (Jarmin and Miranda, 2002). The firm is considered to be operating in the six-digit NAICS industry where the largest share of its employment is housed.

\subsection{Country-level and Country-product-level Data}

The country-level measures are sourced from five public-use databases. First, our primary measure of institutions utilizes data from the World Bank's Doing Business project. We use measures of contract enforcement capturing the cost, days and procedures involved in the legal enforcement of contracts. ${ }^{18}$ We then calculate the principal component of these measures and employ this as our baseline measure of the legal enforcement of contracts. We normalize the measure so that higher values correspond to stronger institutions. The contract enforcement measure is higher when countries implement reforms to better the quality and efficiency of their

\footnotetext{
measurement bias in our spatial concentration index. However, as long as the incidences of such cases is not systematically correlated with our measures of country institutions, our coefficient estimates of these measures of interest will remain unbiased. Nonetheless, a test exduding the largest five countries by population with the premise that larger countries are likely to have larger number of dities that may share the same first three letters shows that our results remain qualitatively robust.

16 Title 19 U.S. Code $1401 \mathrm{a}(\mathrm{g})$ outlines seven different ways in which parties may be related in a U.S. import transaction. The ownership-based definition states firms are related if either owns, controls, or holds voting power equivalent to six percent of the outstanding voting stock or shares of the other organization.

${ }^{17}$ Resource-intensive products are defined as two-digitHS categories 2-14 (agricultural products) and 25-27 (mineral products).

${ }^{18}$ Accessed at http://www.doingbusiness.org/en/data.
} 
court system, for instance, by establishing new commercial courts to lower the workload of existing courts, reduce judicial corruption or introduce electronic case management systems. ${ }^{19}$ The World Bank contract enforcement measures have been used extensively in prior research (for examples see Araujo, Mion, Ornelas, 2016; Feenstra, Hong, Ma, Spencer, 2013).

Second, we utilize data from the Fraser Institute's Economic Freedom of the World index that provides a wide coverage of countries. We focus on the indices of legal structure and security of property rights and freedom to trade internationally. ${ }^{20}$ The index of legal structure and security of property rights is used as an alternative index measuring institutional quality, which measures institutions more broadly. Regulatory trade barriers may be moderated by geographic networks and enters as a control variable in all our regressions. The regulatory trade barriers measure nontariff trade barriers as well as the compliance costs of importing and exporting. The indices range from 0 to 10 where higher numbers correspond to better institutional quality.

Third, we use data on freedom from corruption from the Heritage Foundation as an alternate measure of institutions. ${ }^{21}$ The score varies from 0 to 100 and higher numbers correspond to better measures of freedom. The freedom from corruption score is derived from equally weighting indices for public trust in politicians, irregular payments and bribes, transparency of government policymaking, absence of corruption, perceptions of corruption, and governmental and civil service transparency.

Fourth, we use the World Bank's World Development Indicators (WDI) database to control for country-level characteristics. ${ }^{22}$ We measure information infrastructure as internet technology presence that counts the number of internet users per 100 people. Internet users are defined as "individuals who have used the internet (from any location) in the last 12 months.

\footnotetext{
${ }^{19}$ For example, Estonia made enfording contracts easier by lowering court fees in 2014; Brunei Darussalam made enfording contracts easier by introducing an electronic case management system for the use of judges and lawyers in 2018. See http:/ /www.doingbusiness.org/en/data/exploretopics/enforcing-contracts/reforms for a complete list. 20 See http://www. freetheworld.com/2015/economic-freedom-of-the-world-2015.pdf for detailed description of the index.

${ }^{21}$ Accessed at http://www.heritage.org/index/download.

${ }^{22}$ See http://data.worldbank.org/data-catalog/world-development-indicators for details on data coverage.
} 
Internet can be used via a computer, mobile phone, personal digital assistant, games machine, digital TV etc". This measure captures the ease of information transmission between buyers and sellers for instance, via company websites, portals and electronic communication in general. Superior information infrastructure can mitigate the need for exploiting spatially proximate networks in sourcing decisions. We measure physical infrastructure by the percentage of paved roads as a share of all the country's roads, measured in length, to capture physical infrastructure barriers to dispersed sourcing. Controlling for transportation infrastructure is also important since it has been shown to determine patterns of specialization in cities (Duranton, 2015; Duranton, Morrow, Turner, 2014). The WDI also provides the GDP per capita (in 2010 U.S.D), total population, and land area, all of which enter our specification in logs as control variables for the level of development and country size. Finally, to capture the idea that language barriers might deter information flows and reinforce the need for netw orks in obtaining suppliers, we include an indicator variable if the source country and the U.S. share a commonlanguage sourced from CEPII (Melitz and Toubal, 2014).23

Even though our EG index accounts for the concentration of exports in each product at the country level, we additionally control for differences in industrial concentration across countries. We exploit data on night-lights from Henderson, Storeygard, Weil (2012). ${ }^{24}$ Night-lights data measures lights from human settlements and is therefore a reflection of human activity. Moreover, lights as the measure of economic activity is measured consistently across the world at the same spatial scale. We use the within-country Gini measure of night-lights as a control variable in our analysis.

In addition to the country level variables, we construct and include two additional productcountry variables as controls - the log number of suppliers to the U.S. per product-country and

${ }^{23}$ Accessed at http://www.cepii.fr/cepii/en/bdd modele/presentation.asp?id=19.

${ }^{24}$ The latest available year of inform ation on $\log$ Gini night-lights is 2008 which we utilize in our baseline regressions. 
the log number of cities from which exports to the U.S. originate per product-country, both constructed using the LFT'TD.

\subsection{Analysis Sample}

The analysis sample is constructed using firm-import transactions in the 2011 LFT'TD. $^{25}$ In the LFT'TD, we observe each U.S. firm's imports in every product and the countries that it imports from. ${ }^{26}$ We aggregate the transaction level data at the importer, foreign supplier, and fourdigit product level. About 40 percent of importers source a four-digit HS product from a single supplier accounting for only about 20 percent of total trade value. ${ }^{27}$ By definition of the EG index, single-supplier importers of a particular product will be excluded from our analysis. Therefore, our analysis sample necessarily focuses on importers that source from more than a single supplier within a product-country cell. Once we create an EG index for an importer-product-country triad we obtain a dataset with approximately half a million observations. We trim our analysis dataset for the top and bottom 1 percent of the EG index, dropping about 2 percent of the observations. We then link in country-level measures of institutional quality and control variables described in the previous section. The number of observations differ in each of our specifications due to differential availability and coverage of the country-level variables.

\footnotetext{
${ }^{25}$ In robustness exercises where we show results in different cross-sections, the analysis datasets are constructed in a similarmanner.

${ }^{26}$ Table A3 explores the sourding behavior of U.S. importers across countries. We examine the pro duct and country characteristics that predict if an importer sources a particular product from a country. To investigate the idea that the relationship between a country's institutional quality and the likelihood that a U.S. importer im ports from there may not be monotonic, we indude a squared term of institutional quality. We find that while the coefficient on institutional quality is positive, suggesting that U.S. im porters are more likely to source from institutionally stronger countries, the coefficient on the squared term is negative and statistically significant. This suggests that the likelihood of souring at arm's-length does notincrease as substantially with institutional quality for countries that have very strong institutions, consistent with theidea that in these countries, U.S. importers might prefer to vertically integrate.

${ }^{27}$ We provide correlations between country-level characteristics and single-supplier status and compare im porter size by single-supplier status in the Appendix. Table A1 shows that there is no statistically significant relationship between institutional quality and single-supplier status. Single-supplier status is positively correlated with a country's land area and negatively correlated with the country's population and country level concentration in economicactivity measured by night lights data. Table A2, Panel A, shows that 36\% (39\%) of single (multi) supplier importers are large and account for the bulk $(95 \%)$ of import value as shown in Panel B.
} 


\subsection{Summary Statistics}

In this section we provide descriptive evidence of the relationship between institutional quality and spatial patterns in U.S. importers' global sourcing strategies. Table 1 shows average values in the sample for our main institutional variables and the EG index. In our analysis sample, the average Ellison-Glaeser index, $E G_{m c p}$, is 0.67 while the median is 0.23 . The average costs, days and procedures required to enforce a contract legally are given by 20 percent of claims, 485 days and 36 procedures, respectively. Table 2 shows the average concentration index by broad product categories. ${ }^{28}$ Overall, we find that broad product categories that display the highest average spatial concentration of sourcing tend to be in more hi-tech, capital-intensive industries with the opposite holding true for categories displaying the lowest average concentration. The exceptions are vegetable products, leather and footwear.

Figure 1 displays a world map showing values of the average EG index across countries. Darker colors correspond to greater concentration while lighter colors indicate lower concentration. We note that there is substantial variation in the concentration index even within country groups defined across various dimensions like land area (medium levels of concentration in China and Canada versus high concentration in Russia), population (India versus China) and level of development (variation in concentration within Africa and Europe and across middleincome countries like Brazil, Russia and South Africa).

Table 3 further displays the average spatial concentration by importer size and institutional quality. In panel A, importers are classified as large (employs 500+ workers), medium (employs 250-499 workers), and small (employs $<250$ workers). We find that large importers exhibit higher values of the EG index compared to small and medium importers. In panel $\mathrm{B}$, countries are classified into three quantiles by the principal component measure of enforcement of contracts using the World Bank's three separate measures of contract enforcement. We find that countries

\footnotetext{
28 The broad product dassifications are based on groupings of various two-digit HS product categories. See
} http://www.foreign-trade.com/reference/hscode.htm. 
in the top quantile with the strongest institutions display much lower spatial concentration of sourcing relative to countries in the middle and lower quantiles. The spatial concentration index is greater for countries in the middle quantile of contract enforcement than for countries in the lower quantile, hinting at a non-linearity in the unconditional relationship between spatial concentration and institutions. Figure 2 displays a scatter plot of the average EG index values within twenty bins of institutional quality and demonstrates a similar pattern of a non-monotonic unconditional relationship. Better institutional quality is initially associated with greater supplier concentration but the relationship is negative for higher levels of institutional quality.

From Table 4, column 1, we find that an importer sources from 1.79 countries on average. However, this masks variation by importer size. We find that large and medium importers source from 2.4 to almost 3 countries respectively, while small importers source from 1.57 countries on average. In column 2, we present corresponding figures by importer-product pair. We find that an importer sources a particular product from about 1.4 countries on average. Larger importers tend to source from more countries than smaller importers. On average, large importers source from 1.79 countries, while medium and small importers source from 1.46 and 1.24 countries, respectively.

Next, in Table 5, we document the distribution of the number of suppliers per importerproduct-country by importer size. In panel $\mathrm{A}$, as expected, we find that larger importers tend to source from more suppliers on average and at the $75^{\text {th }}$ percentile within a particular product and country compared to medium and small importers. At the $25^{\text {th }}$ percentile of the distribution and at the median, there is no variation in the number of suppliers per importer-country-product by firm size. Panel B reveals that importers, on average, tend to source more from countries with better institutional quality. The $25^{\text {th }}, 50^{\text {th }}$, and $75^{\text {th }}$ percentiles display similar variation as in Panel A. Overall, the descriptive analyses suggest that higher institutional quality is associated with lower spatial concentration of sourcing by U.S. importers. In the next section, we rigorously test this relationship by estimating versions of equation (3.2). 


\section{Results}

\subsection{Institutions and Spatial Concentration of Sourcing}

Table 6 presents estimates of equation (3.2), using confidential U.S. firm-import transactions linked data in 2011. We estimate the relationship between institutional quality and spatial concentration of sourcing by U.S. importers, captured by an EG index. Columns (1) through (3) present results for the various measures of contract enforcement at the country-level - the cost, number of procedures and number of days required to legally enforce contracts. The World Bank measures contract enforcement by collecting data on the number of procedures required to enforce a contract through the courts, the number of days required to complete procedures, and the cost required to complete procedures, measured as a percentage of claim. In column (4), we use the principal component of these measures as the key institutional variable, which we use in all subsequent regressions as our baseline measure of institutions. We normalize the measures of institutions so that higher values correspond to stronger contract enforcement.

Specifications across all columns include controls for infrastructure (information and transportation) quality and for regulatory trade barriers. We also control for the source country's level of development (GDP per capita), population, land area, common language with the U.S., concentration of economic activity (Gini of night-lights) and the total number of suppliers and cities per country-product. Finally, all columns include importer and product fixed effects to account for time-invariant importer and product heterogeneity.

From columns (1) through (4), we find that with the full battery of control variables, except for column (1), our measures of contract enforcement are negatively related to the spatial concentration of sourcing. Coefficients are statistically significant at the five percent level. Results from column (2) indicate that a decrease of ten in the number of procedures required to legally enforce a contract (about $28 \%$ of the mean across countries) is associated with a decrease in the EG spatial concentration index of 0.5. A decrease of one standard deviation in the number of procedures required to legally enforce a contract is associated with a 0.10 standard deviation 
decrease in the EG spatial concentration index. Results from column (3) indicate that a decrease of a hundred in the number of days required to legally enforce a contract (about $21 \%$ of the mean across countries) is associated with a decrease in the EG spatial concentration index of 0.1. A decrease of one standard deviation in the number of days required to legally enforce a contract is associated with a 0.08 standard deviation decrease in the EG spatial concentration index.

A potential explanation for the large standard errors on the coefficient estimate of the cost of contract enforcement (shown in Column 1) is that the cost of contract enforcement is a noisy measure of the actual ease with which contracts can be legally enforced. We note that the cost measure only captures the formal costs associated with contract enforcement and does not include informal costs like bribes. Countries with high levels of corruption are characterized by more onerous regulations (Ahsan, 2017) that are more easily exploited by dishonest officials to extract bribes (for example corruption can drive up trade costs, De Jong and Bogmans, 2011). Subsequently, in institutionally weak environments, bribes are likely to be a significant proportion of enforcement costs. The time and number of procedures involved in enforcing contracts are less likely to suffer from measurement error leading to attenuation bias.

Overall, we do not find a statistically significant relationship between infrastructure and regulatory trade barriers and our dependent variable, suggesting that these are not important determinants of the spatial concentration of global sourcing. A country's level of development, population, number of cities exporting to the U.S. from a country-product and concentration of economic activity in the country are positively related, while land area, common language and the number of suppliers to the U.S. in a country-product are negatively related to the spatial concentration of sourcing.

In Table 7, column (1), we present results from the instrumental variables estimation. We instrument for contract enforcement with legal origins following Nunn (2007). Legal origins are highly correlated with contemporary institutions due to path-dependence in institutions. The exclusion restriction is derived from the idea that while a country's legal origins are correlated with 
current institutional quality, they are not correlated with unobserved factors affecting the current spatial concentration of sourcing. We expect that countries with legal origins rooted in British common law to have stronger institutions than countries with legal origins rooted in German, Scandinavian or French (civil) law. We separately include an indicator for countries with a Socialist legal origin. These countries, comprising primarily of former Soviet Union and Eastern European countries, may have transitioned over time to their pre-Russian revolution or pre-World War II legal systems which were French or German civil law (La Porta, Lopez-de-Silanes, Shleifer, 2008).

In our first-stage regression, we regress dummies for civil (French, German or Scandinavian), Socialist, and British (the left-out category) legal origins on the principal component measure of contract enforcement. The first stage is significant (F-statistic $=13.99)$ and we find a negative relationship between the civil legal origin dummy and contract enforcement. This is consistent with a legal origin rooted in civil law is more likely to be associated with weaker institutions than a legal origin rooted in common law. We find a positive relationship between contract enforcement and the Socialist legal origin dummy. We test for weak instruments using the Hansen J-statistic. The statistic of 1.93 with a p-value of 0.17 does not allow us to reject the null hypothesis that the over-identifying restrictions are valid.

Second-stage results are presented in column (1) of Table 7. These results reinforce our baseline finding from column (4), Table 6, showing a negative and significant relationship between institutional quality and the spatial concentration of sourcing. The instrumental-variables result shows a larger negative relationship between institutions and the spatial concentration of sourcing, hinting at attenuation bias in the OLS estimates due to measurement error. Unobserved factors that lead to weaker contract enforcement regimes but decrease supplier concentration could also lead to a downward bias in the OLS coefficients.

In column (2) of Table 7, we include a set of importer-product fixed effects. The goal is to account for unobserved heterogeneity at the importer-product level that may be correlated with institutional quality of countries that importers source from and supplier concentration 
simultaneously. The coefficient on institutional quality is negative and significant, reinforcing the baseline results in column (4) of Table 6.

\subsection{Robustness Checks}

Tables 8 and 9 provide results from further robustness checks of our baseline result in column 4, Table 6. In columns (1) through (3) of Table 8, we estimate equation (3.2) with all our control variables for years, separately, between 2008 and 2010. The coefficient on contract enforcement is remarkably robust and varies between -0.13 and -0.15 . These results confirm that the observed negative relationship between institutional quality and spatial concentration of suppliers is not driven by the choice of sample year.

In columns (1) and (2) of Table 9, we present results using two alternate measures of institutional quality. We use the Fraser Institute's comprehensive index of legal system and property rights, and the Heritage Foundation's freedom from corruption measure. The former is a broader measure of institutional quality, while the latter captures an alternate dimension of institutions that impacts contract enforcement. Corruption introduces uncertainty in economic relationships that may exacerbate the costs to importers of seeking legal redress in the event of default. The results support our baseline finding - poor institutional quality is associated with higher spatial concentration of sourcing. In column (3), we use a count-based EG index instead of a value-based EG index to measure concentration. This alternate index uses the number of suppliers, instead of value of imports sourced from these suppliers to calculate the EG measure of concentration. Again, we find that our result holds qualitatively.

Overall, results in Tables 8 and 9 provide strong and robust support that weaker institutions are associated with greater concentration of sourcing by U.S. importers. Centralization forces hence dominate decentralization forces under weak institutions. In the next section, we explore the potential centralization forces in detail. 


\subsection{Potential Channels}

Our main results firmly establish that weaker institutions are associated with higher supplier concentration. Thus, channels whereby U.S. importers diversify risk from catastrophic events by sourcing in a dispersed fashion from countries with weak institutions are unlikely to be dominant. In this section, we explore alternative channels underlying the relationship between weak institutions and higher spatial concentration of foreign suppliers discussed in our conceptual framework.

First, the observed relationship between institutional quality and supplier concentration may be driven by the fact that economic activity in institutionally weak countries is likely to be concentrated in large primate cities (Ades and Glaeser, 1995). To evaluate this idea, we reconstruct the index of supplier concentration after excluding foreign suppliers located in primate cities. We obtain a list of primate cities from the World Heritage Encyclopedia. A primate city is defined as a city which is at least twice as populous as the second largest city in the country. ${ }^{29} \mathrm{We}$ then reestimate our baseline specification.

Second, the observed relationship between supplier concentration and institutional quality may be driven by the nature of the foreign supplier's economic activities, specifically, if the foreign supplier is an intermediary. Intermediaries (rather than manufacturers) may concentrate more near distribution centers such as ports. If exports from developing countries that also have weak institutions are routed more extensively through intermediaries, we may observe an association between supplier concentration and institutional quality for this reason. We reconstruct the EG index excluding foreign suppliers that may be intermediaries and re-estimate our baseline specification. We define a foreign supplier as a potential intermediary if the supplier exports more than ten HS two-digit products following Kamal and Monarch (2018). Intermediaries, unlike manufacturers, are more likely to transact across a wide range of products.

\footnotetext{
29 Accessed at http://worldlibrary.net/articles $/$ list $\% 20 \mathrm{of} \% 20$ primate $\% 20$ cities? \&words=cities $\% 20$ in $\% 20$ mexico on January 13,2018 . Note that not all countries have a primate dity.
} 
Table 10 shows results using the EG index reconstructed using the two distinct samples of foreign suppliers. Column (1) of'Table 10 shows results for the estimation that excludes primate cities in countries where they exist. In column (2), the dependent variable excludes foreign suppliers that export more than ten HS two-digit products and hence are likely to be trading intermediaries rather than manufacturers. Across both columns, we find that our baseline result holds qualitatively. This suggests that the two channels evaluated here are not the only drivers of the relationship we identify between institutional quality and supplier concentration.

Finally, we argue that in a setting where formal institutions are weak, supplier networks can lower costs of matching and transacting by facilitating information flows and sanctioning contract violations between trading partners. Though we are unable to provide direct evidence on the role of supplier networks, we further explore the idea that supplier networks can lower the costs of matching and transacting by spreading information and sanctioning contract violations by estimating equation (3.3).

Results in Table 11, column (1) suggest that indeed, the coefficient on the interaction between institutional quality and contract intensity is negative and statistically significant as hypothesized. This suggests that weak institutional quality is associated with more concentration in sourcing for importers in industries that are more contract intensive, providing further evidence for the role of supplier networks. We find that the coefficient on the triple-interaction term is positive but statistically insignificant, suggesting that the differential relationship between institutional quality and supplier concentration for importers in contract intensive industries is not more pronounced when U.S. importer bargaining power is greater.

In column (2), we investigate if there exists a non-linear relationship between institutional quality and supplier concentration as suggested by the summary statistics (Table 3, Panel B and Figure 2) and whether it persists once we account for other factors related to both institutional quality and supplier concentration. We introduce a squared term of the contract enforcement variable to our baseline specification in (3.2). We do not find evidence for a non-linear relationship 
once we account for other factors that are related to both institutional quality and supplier concentration.

\section{Conclusion}

This paper explores the role of a source country's institutional environment in shaping the patterns of spatial concentration of industrial activity by studying the global sourcing strategies of U.S. importers. We find that weaker institutions are associated with greater concentration of sourcing by U.S. importers. This result is robust to including a battery of control variables and an instrumental-variables estimation strategy to account for the endogeneity of institutions, using alternate measures of institutions and the spatial concentration of sourcing, and utilizing samples in different years. An exploration of the various channels driving this relationship yields support for the idea that supplier networks can mitigate the costs imposed by weak institutions due to contractual frictions.

Our study highlights the role for institutions in driving spatial patterns in sourcing strategies by firms and thereby proposes institutional quality as a determinant of concentration of industrial activity. We offer initial evidence in support of information spillovers that may arise in supplier networks above and beyond local export spillovers in the presence of weak institutions. In addition to contributing to the literatures on urban agglomeration and international trade, we augment the literature studying how informal institutions may foster economic activity, particularly, the role of informal cooperative coalitions in promoting efficiency by reducing agency and other transactions costs in the absence of strong formal enforcement institutions. 


\section{References}

Ades, Alberto F., and Edward L. Glaeser. 1995. "Trade and Circuses: Explaining Urban Giants," Quarterly Journal of Economics 110(1): 195-227.

Ahn, JaeBin, Amit K. Khandelwal, and Shang-Jin Wei, "The Role of Intermediaries in Facilitating Trade," Journal of International Economics, 2011, 84(1): 73-85.

Ahsan, Reshad. 2017. "Does Corruption Attenuate the Effect of Red Tape on Exports," Economic Inquiry 55(3): 1192-1212.

Antràs, Pol, 2015. Global Production: Firms, Contracts, and Trade Structure. Princeton University Press.

Antràs, Pol, and Elhanan Helpman. 2008. "Contractual Frictions and Global Sourcing." In The Organization of Firms in a Global Economy, eds. Elhanan Helpman, Dalia Marin, and Thierry Verdier, 9-54. Cambridge, MA: Harvard University Press.

Araujo, Luis, Giordano Mion, and Emanuel Ornelas. 2016. "Institutions and Export Dynamics," Journal of International Economics, 98: 2-20.

Audretsch, David B and Maryann P. Feldman. 1996. "R\&D Spillovers and the Geography of Innovation and Production," American Economic Review 86(3): 630-40.

Bernard, Andrew A., J. Brad ford Jensen, Stephen J. Redding, and Peter K. Schott. 2010. "Intrafirm Trade and Product Contractibility," American Economic Revien Papers and Proceedings 100: 444-448.

Chauvin, Juan Pablo, Edward Glaeser, Yueran Ma, and Kristina Tobio. 2017. "What is Different about Urbanization in Rich and Poor Countries? Cities in Brazil, China, India, and the United States," Journal of Urban Economics 98: 17-49.

Cole, Matthew A., Robert J. R. Elliott, Toshihiro Okubo, and Eric Strobl. 2017. "Pre-disaster Planning and Post-Disaster Aid: Examining the Impact of the Great East Japan Earthquake," International Journal of Disaster Risk Reduction 21: 291-302.

De Jong, Eelke, and Christian Bogmans. 2011. "Does Corruption Discourage International Trade" European Journal of Political Economy 27: 385-398.

Dell, Melissa, and Benjamin A. Olken. 2017. "The Development Effects of the Extractive Colonial Economy: The Dutch Cultivation System in Java,” NBER Working Paper No. 24009.

Duranton, Gilles. 2015. "Roads and Trade in Colombia," Economics of Transportation 4(1): 16-36.

Duranton, Gilles, Peter Morrow, and Matthew Turner. 2014. "Roads and Trade: Evidence from the U.S.," Review of Economic Studies 81(2): 681-724.

Ellison, Glenn, and Edward L. Glaeser. 1997. "Geographic Concentration in U.S. Manufacturing Industries: A Dartboard Approach,” Journal of Political Economy 105(5): 889-927.

Feenstra, Robert, Chang Hong, Hong Ma, Barbara J. Spencer. 2013. "Contractual versus NonContractual Trade: The Role of Institutions in China," Journal of Economic Behavior and Organization 94:281-294. 
Fernandes, Ana P., Tang, Heiwai, 2014. "Learning to Export from Neighbors," Journal of International Economics 94(1): 87-94.

Glaeser, Edward L., and Joshua D. Gottlieb. 2009. "The Wealth of Cities: Agglomeration Economies and Spatial Equilibrium in the United States," Journal of Economic Literature 47 (4): 9831028.

Greif, Avner. 1993. "Contract Enforceability and Economic Institutions in Early Trade: The Maghribi Traders' Coalition,” American Economic Review 83(3): 525-548.

Haraguchi, Masahiko, and Upmanu Lall. 2015. "Flood risks and Impacts: A Case Study of Thailand's Floods in 2011 and Research Questions for Supply Chain Decision Making," International Journal of Disaster Risk Reduction 14(3): 256-272.

Henderson, J., Vernon. 2003. "Marshall's Scale Economies," Journal of Urban Economics 53: 1-28.

Henderson, J., Vernon, Adam Storeygard, and David N. Weil. 2012. "Measuring Economic Grow th from Outer Space," American Economic Review 102(2): 994-1028.

Henriet, Fanny, Stephanie Hallegatte, and Lionel Tabourier. 2012. "Firm-Network Characteristics and Economic Robustness to Natural Disasters," Journal of Economic Dynamics and Control 36: 150167.

Jarmin, Ron, S., and Javier Miranda. 2002. “The Longitudinal Business Database,” U.S. Census Bureau Center for Economic Studies Working Paper 02-17.

Kamal, Fariha, and Ryan Monarch. 2018. "Identifying Foreign Suppliers in U.S. Import Data," Review of International Economics 26(1): 117-139.

Kamal, Fariha, and Asha Sundaram. 2016. "Buyer-Seller Relationships in International Trade: Do your Neighbors Matter?” Journal of International Economics 102: 128-140.

Knemeyer, Michael A., Zinn Walter, and Cuneyt Eroglu. 2009. "Proactive Planning for Catastrophic Events in Supply Chains," Journal of Operations Management 27(2):141-153.

Koenig, Pamina. 2009. "Agglomeration and the Export Decisions of French Firms," Journal of Urban Economics 66: 186-195.

Koenig, Pamina, Florian Mayneris, and Sandra Poncet. 2010. "Local Export Spillovers in France," European Economic Review 54: 622-641.

La Porta, Rafael, Florencio Lopez-de-Silanes, and Andrei Shleifer. 2008. "The Economic Consequences of Legal Origins," Journal of Economic Literature 46(2): 285-332.

Levchenko, Andrei. 2007. "Institutional Quality and International Trade," Review of Economic Studies 74(3): 791-819.

Lovely, Mary E., Stuart Rosenthal, and Shalini Sharma. 2005. "Information, Agglomeration, and the Headquarters of U.S. Exporters," Regional Science and Urban Economics 35: 167-191. 
McMillan, John, and Christopher Woodruff. 1999. "Inter-firm Relationships and Informal Credit in Vietnam," Quarterly Journal of Economics 114(4): 1285-1320.

Melitz, Jacques, and Farid Toubal. 2014. "Native Language, Spoken Language, Translation and Trade," Journal of International Economics 92(2): 351-363.

Nunn, Nathan. 2007. "Relationship-Specificity, Incomplete Contracts and the Pattern of Trade," Quarterly Journal of Economics 122(2): 569-600.

Nunn, Nathan, and Daniel Trefler. 2014. "Domestic Institutions as a Source of Comparative Advantage," in Gita Gopinath, Elhanan Helpman, and Kenneth Rogoff (eds.), Handbook of International Economics. Vol. 4, Elsevier, North Holland, pp. 263-315.

Puga, Diego. 2010. "The Magnitude and Causes of Agglomeration Economies," Journal of Regional Science 50(1): 203-219.

Ramondo, Natalia, Veronica Rappoport, and Kim J. Ruhl. 2016. "Intrafirm Trade and Vertical Fragmentation in U.S. Multinational Corporations," Journal of International Economics 98: 51-59.

Rosenthal, Stuart and William Strange. 2004. "Evidence on the Nature and Sources of Agglomeration Economies," in J. Vernon Henderson and Jacques F. Thisse (eds.), Handbook of Regional and Urban Economics. Vol. 4, Elsevier North-Holland, pp. 2119-2171. 
Table 1. Summary Statistics, 2011

\begin{tabular}{ccc}
\hline Variable & Mean & Standard Deviation \\
\hline Contract Enforcement - Cost & 20.291 & 19.044 \\
Contract Enforcement - Days & 484.629 & 277.034 \\
Contract Enforcement - Procedures & 36.155 & 4.681 \\
Contract Enforcement - Principal Component & 0.009 & 1.252 \\
EG Index (value) & 0.669 & 2.842 \\
\hline
\end{tabular}

Notes: This table displays average institutional quality and spatial concentration of sourcing per importer-country. The World Bank measures contract enforcement by the cost required to complete procedures and measured as a percentage of claim (Contract Enforcement - Cost), the number of days required to complete procedures (Contract Enforcement - Days), and the number of procedures required to enforce a contract through the courts (Contract Enforcement - Procedures). The EllisonGlaeser (EG) Index is as defined in (3.1).

Table 2. Spatial concentration of sourcing using EG Index, by Product Classification, 2011

\begin{tabular}{ccc}
\hline Broad Product Categories & Mean & Standard Deviation \\
\hline Animal \& Animal Products & 0.555 & 2.837 \\
Vegetable Products & 0.737 & 3.185 \\
Prepared Foodstuffs & 0.514 & 2.612 \\
Chemical \& Allied Industries & 0.993 & 3.579 \\
Plastics \& Rubber & 0.718 & 2.932 \\
Raw Hides, Skins, Leather, \& Furs & 0.799 & 3.133 \\
Wood \& Wood Products & 0.497 & 2.320 \\
Textiles & 0.584 & 2.789 \\
Footwear \& Headgear & 0.694 & 3.182 \\
Stone \& Glass & 0.539 & 3.033 \\
Metals & 0.705 & 2.948 \\
Machinery \& Electrical & 0.749 & 2.838 \\
Transportation & 0.781 & 2.938 \\
Miscellaneous & 0.654 & 2.762 \\
All & 0.678 & 2.873 \\
\hline
\end{tabular}

Notes: This table displays the average supplier concentration measured as the Ellison-Glaeser (EG) index as defined in (3.1) by twodigit HS product categories following http://www.foreign-trade.com/reference/hscode.htm. 
Table 3. Spatial concentration of sourcing using EG Index, 2011

\begin{tabular}{cc}
\hline Panel A: By Importer Size & \\
\hline Firm Size & Average (s.d) \\
\hline Large (500+) & $0.698(2.973)$ \\
Medium $(250-499)$ & $0.643(2.907)$ \\
Small $(<250)$ & $0.651(2.740)$ \\
\hline Panel B: By Institutional Quality & \\
\hline Country Group & Average (s.d) \\
\hline High & $0.469(1.851)$ \\
Middle & $0.865(3.380)$ \\
Low & $0.752(2.774)$ \\
\hline
\end{tabular}

Notes: This table displays the average supplier concentration measured as the Ellison-Glaeser (EG) index as defined in (3.1) with standard deviation in parentheses. Importers are classified into three size bins: "large" employs more than 500 workers, "medium" employs between 250 and 500 workers, and "small" employs less than 250 workers. Countries are divided into three quantiles of institutional quality captured by ease of contract enforcement.

Table 4. Number of source countries, 2011

\begin{tabular}{ccc}
\hline Firm Size & Average \\
\hline & Importer & Importer-Product \\
\hline Large $(500+)$ & 2.42 & 1.79 \\
Medium $(250-499)$ & 2.92 & 1.46 \\
Small $(<250)$ & 1.57 & 1.24 \\
All & 1.79 & 1.40 \\
\hline
\end{tabular}

Notes: This table displays the average number of countries that an importer (Column 1) and importer-product pair (Column 2) sources from. Importers are classified into three size bins: "large" employs more than 500 workers, "medium" employs between 250 and 500 workers, and "small" employs less than 250 workers.

Table 5. Number of suppliers per importer-product-country, 2011

\section{Panel A: By Importer Size}

25 ${ }^{\text {th }}$ percentile Median

$75^{\text {th }}$ percentile

Average (s.d.)

\begin{tabular}{cllcc}
\hline Firm Size & & & & \\
\hline Large (500+) & 2 & 3 & 4.34 & $5.24(11.98)$ \\
Medium (250-499) & 2 & 2 & 4 & $4.15(9.40)$ \\
Small (<250) & 2 & 2 & 3.31 & $3.51(4.29)$ \\
\hline Panel B: By Institutional Quality & & & & \\
\hline Country Group & 2 & 3 & 4.38 & $5.04(10.34)$ \\
High & 2 & 2 & 4 & $3.77(5.60)$ \\
Medium & 2 & 2 & 4 & $3.97(8.95)$ \\
Low &
\end{tabular}

Notes: This table displays the $25^{\text {th }}$ percentile, median, the $75^{\text {th }}$ percentile, average and the standard deviation (in parentheses) of the number of suppliers per importer-product-country triad. Importers are classified into three size bins: "large" employs more than 500 workers, "medium" employs between 250 and 500 workers, and "small" employs less than 250 workers. Countries are divided into three quantiles of institutional quality captured by ease of contract enforcement. 
Table 6. Spatial Concentration of Foreign Suppliers and the Role of Institutions, 2011

\begin{tabular}{|c|c|c|c|c|}
\hline Dependent Variable: EG Index Value & $\begin{array}{c}(1) \\
\text { Cost }\end{array}$ & $\begin{array}{c}(2) \\
\text { Procedures }\end{array}$ & $\begin{array}{c}(3) \\
\text { Days }\end{array}$ & $\begin{array}{c}(4) \\
\text { Principal Component }\end{array}$ \\
\hline Contract Enforcement & $\begin{array}{c}0.001 \\
(0.002)\end{array}$ & $\begin{array}{l}-0.049^{* *} \\
(0.019)\end{array}$ & $\begin{array}{l}-0.001^{* *} \\
(0.000)\end{array}$ & $\begin{array}{l}-0.169^{* *} \\
(0.085)\end{array}$ \\
\hline Regulatory Trade Barrier & $\begin{array}{l}-0.146 \\
(0.139)\end{array}$ & $\begin{array}{l}-0.070 \\
(0.120)\end{array}$ & $\begin{array}{l}-0.027 \\
(0.127)\end{array}$ & $\begin{array}{l}-0.135 \\
(0.142)\end{array}$ \\
\hline Internet per 100 people & $\begin{array}{l}-0.014 \\
(0.011)\end{array}$ & $\begin{array}{l}-0.015^{*} \\
(0.008)\end{array}$ & $\begin{array}{l}-0.010 \\
(0.010)\end{array}$ & $\begin{array}{l}-0.009 \\
(0.011)\end{array}$ \\
\hline \% Paved Roads & $\begin{array}{l}-0.002 \\
(0.004)\end{array}$ & $\begin{array}{c}0.002 \\
(0.004)\end{array}$ & $\begin{array}{l}-0.002 \\
(0.004)\end{array}$ & $\begin{array}{l}-0.001 \\
(0.004)\end{array}$ \\
\hline Log GDP Per Capita (constant 2010 USD) & $\begin{array}{l}0.485^{*} \\
(0.257)\end{array}$ & $\begin{array}{l}0.673^{* * *} \\
(0.235)\end{array}$ & $\begin{array}{l}0.708^{* *} \\
(0.269)\end{array}$ & $\begin{array}{l}0.621^{* *} \\
(0.269)\end{array}$ \\
\hline Log Population & $\begin{array}{l}0.170^{+} \\
(0.110)\end{array}$ & $\begin{array}{l}0.152^{*} \\
(0.087)\end{array}$ & $\begin{array}{l}0.330^{* * *} \\
(0.122)\end{array}$ & $\begin{array}{l}0.180^{*} \\
(0.106)\end{array}$ \\
\hline Log Land Area & $\begin{array}{l}-0.126 \\
(0.109)\end{array}$ & $\begin{array}{l}-0.083 \\
(0.085)\end{array}$ & $\begin{array}{l}-0.244^{* *} \\
(0.113)\end{array}$ & $\begin{array}{l}-0.085 \\
(0.098)\end{array}$ \\
\hline Common Language & $\begin{array}{c}-0.219^{+} \\
(0.147)\end{array}$ & $\begin{array}{l}-0.230^{* *} \\
(0.111)\end{array}$ & $\begin{array}{c}-0.581^{* * *} \\
(0.165)\end{array}$ & $\begin{array}{l}-0.355^{* *} \\
(0.164)\end{array}$ \\
\hline Log Gini Lights (2008) & $\begin{array}{l}1.577^{*} \\
(0.899)\end{array}$ & $\begin{array}{l}1.662^{* *} \\
(0.659)\end{array}$ & $\begin{array}{l}2.925^{* * *} \\
(0.950)\end{array}$ & $\begin{array}{l}1.591^{* *} \\
(0.791)\end{array}$ \\
\hline Log \# Suppliers per Product-Country & $\begin{array}{c}-0.584^{* * *} \\
(0.095)\end{array}$ & $\begin{array}{c}-0.453^{* * *} \\
(0.073)\end{array}$ & $\begin{array}{c}-0.419^{* * *} \\
(0.082)\end{array}$ & $\begin{array}{c}-0.416^{* * *} \\
(0.090)\end{array}$ \\
\hline Log \# Cities per Product-Country & $\begin{array}{c}0.582^{* * *} \\
(0.149)\end{array}$ & $\begin{array}{c}0.405^{* * *} \\
(0.128)\end{array}$ & $\begin{array}{l}0.332^{* *} \\
(0.138)\end{array}$ & $\begin{array}{l}0.358^{* *} \\
(0.153)\end{array}$ \\
\hline
\end{tabular}

Notes: Number of observations equals 245,000 and rounded for disclosure avoidance. Column headings for columns 1 through 4 list the various measures of contract enforcement used as the key independent variable. The dependent variable is as defined in (3.1). All columns include Importer and HS4 product fixed effects. Standard errors clustered by country in parentheses. $*<0.10, * *<0.05 ; * * *<0.01$. 
Table 7. Spatial Concentration of Foreign Suppliers and the Role of Institutions, Alternate Specifications

\begin{tabular}{|c|c|c|}
\hline Dependent Variable: EG Index Value & $\begin{array}{l}\text { (1) } \\
\text { IV }\end{array}$ & $\begin{array}{c}(2) \\
\text { Importer } x \text { Product }\end{array}$ \\
\hline Contract Enforcement & $\begin{array}{l}-0.228^{*} \\
(0.121)\end{array}$ & $\begin{array}{l}-0.146^{* *} \\
(0.067)\end{array}$ \\
\hline Regulatory Trade Barrier & $\begin{array}{l}-0.124 \\
(0.149)\end{array}$ & $\begin{array}{l}-0.410 \\
(0.124)\end{array}$ \\
\hline Internet per 100 people & $\begin{array}{l}-0.008 \\
(0.011)\end{array}$ & $\begin{array}{l}-0.006 \\
(0.010)\end{array}$ \\
\hline$\%$ Paved Roads & $\begin{array}{l}-0.000 \\
(0.004)\end{array}$ & $\begin{array}{l}-0.003 \\
(0.003)\end{array}$ \\
\hline Log GDP Per Capita (constant 2010 USD) & $\begin{array}{l}0.672^{* *} \\
(0.291)\end{array}$ & $\begin{array}{l}0.423^{*} \\
(0.247)\end{array}$ \\
\hline Log Population & $\begin{array}{l}0.189^{*} \\
(0.111)\end{array}$ & $\begin{array}{c}0.094 \\
(0.112)\end{array}$ \\
\hline Log Land Area & $\begin{array}{l}-0.078 \\
(0.100)\end{array}$ & $\begin{array}{l}-0.065 \\
(0.096)\end{array}$ \\
\hline Common Language & $\begin{array}{l}-0.404^{* *} \\
(0.196)\end{array}$ & $\begin{array}{c}-0.369^{* * *} \\
(0.132)\end{array}$ \\
\hline Log Gini Lights (2008) & $\begin{array}{l}1.657^{* *} \\
(0.819)\end{array}$ & $\begin{array}{l}1.135 \\
(0.705)\end{array}$ \\
\hline Log \# Suppliers per Product-Country & $\begin{array}{c}-0.363^{* * *} \\
(0.114)\end{array}$ & $\begin{array}{c}-0.443^{* * *} \\
(0.088)\end{array}$ \\
\hline Log \# Cities per Product-Country & $\begin{array}{l}0.286 \\
(0.187)\end{array}$ & $\begin{array}{c}0.472^{* * *} \\
(0.126)\end{array}$ \\
\hline Observations & 245,000 & 245,000 \\
\hline Fixed Effect & Importer, HS4 & Importer x HS4 \\
\hline
\end{tabular}


Table 8. Spatial Concentration of Foreign Suppliers and the Role of Institutions, Alternate Years

\begin{tabular}{lccc}
\hline Dependent Variable: EG Index Value & $(1)$ & $(2)$ & $(3)$ \\
& $\mathbf{2 0 0 8}$ & $\mathbf{2 0 0 9}$ & $\mathbf{2 0 1 0}$ \\
\hline Contract Enforcement & $-0.149^{* *}$ & $-0.142^{* *}$ & $-0.132^{*}$ \\
& $(0.066)$ & $(0.070)$ & $(0.074)$ \\
Regulatory Trade Barrier & -0.238 & -0.171 & -0.216 \\
& $(0.142)$ & $(0.123)$ & $(0.141)$ \\
Internet per 100 people & -0.001 & -0.007 & -0.008 \\
& $(0.008)$ & $(0.008)$ & $(0.009)$ \\
\% Paved Roads & -0.002 & -0.001 & 0.001 \\
& $(0.004)$ & $(0.004)$ & $(0.003)$ \\
Observations & & & \\
Fixed Effect & 222,000 & 214,000 & 242,000 \\
\hline
\end{tabular}

Notes: Number of observations rounded for disclosure avoidance. Column headings denote the sample years. The dependent variable is as defined in (3.1). The following control variables are included in all specifications: log GDP per capita (con stant 2010 USD), $\log$ population, $\log$ land area, common language indicator, $\log$ gini lights, log number of suppliers per productcountry, $\log$ number of cities per product-country. Standard errors clustered by country in parentheses. $*<0.10, * *<0.05$; *** $<0.01$.

Table 9. Spatial Concentration of Foreign Suppliers and the Role of Institutions, Alternate Measures

(1) (2) (3)

Dependent Variable: EG Index Value EG Index Value EG Index Count

Contract Enforcement $-0.120^{\text {*** }}$

Legal System \& Property Rights $\quad-0.232^{* * *}$

Freedom from Corruption $-0.017^{* *}$

(0.006)

Regulatory Trade Barrier

$-0.075$

$-0.059$

$-0.017$

Internet per 100 people

$-0.003$

$-0.008$

$0.022^{* * *}$

(0.008)

$(0.007)$

$(0.005)$

\% Paved Roads

0.000

0.000

$0.005^{* *}$

(0.003)

(0.004)

(0.002)

Observations

245,000

Fixed Effect

Importer, HS4

Notes: Number of observations rounded for disclosure avoidance. The dependent variable in columns 1 and 2 is as defined in (3.1) and in column 3 is similarly defined, except it uses the count of suppliers. In column 1, we use an alternate measure of institutional quality from the Fraser Institute. In column 2, we use the freedom from corruption measure from the Heritage Foundation. The following control variables are included in all specifications: log GDP per capita (constant 2010 USD), log population, $\log$ land area, common language indicator, $\log$ gini lights, $\log$ number of suppliers per product-country, $\log$ number of cities per product-country. Standard errors clustered by country in parentheses. $*<0.10, * *<0.05 ; * * *<0.01$. 
Table 10. Spatial Concentration of Foreign Suppliers and the Role of Institutions, Potential Channels

\begin{tabular}{|c|c|c|}
\hline Dependent Variable: EG Index Value & +2 & $(2)$ \\
\hline & Exclude Primate Cities & Exclude Intermediary Suppliers \\
\hline Contract Enforcement & $\begin{array}{c}-0.157^{* *} \\
(0.076)\end{array}$ & $\begin{array}{c}-0.179^{* *} \\
(0.067)\end{array}$ \\
\hline Regulatory Trade Barrier & $\begin{array}{l}-0.151 \\
(0.138)\end{array}$ & $\begin{array}{l}-0.217 \\
(0.133)\end{array}$ \\
\hline Internet per 100 people & $\begin{array}{l}-0.008 \\
(0.010)\end{array}$ & $\begin{array}{l}-0.006 \\
(0.003)\end{array}$ \\
\hline$\%$ Paved Roads & $\begin{array}{l}-0.000 \\
(0.003)\end{array}$ & $\begin{array}{l}-0.003 \\
(0.003)\end{array}$ \\
\hline Observations & 231,000 & 166,000 \\
\hline Fixed Effect & \multicolumn{2}{|c|}{ Importer, HS4 } \\
\hline
\end{tabular}

Table 11. Spatial Concentration of Foreign Suppliers and the Role of Institutions, Extensions

\begin{tabular}{lr}
\hline Dependent Variable: EG Index Value & $(1)$ \\
\hline Contract Enforcement x Contract Intensity & $-0.805^{*}$ \\
& $(0.447)$ \\
Contract Enforcement x Importer Concentration & -1.110 \\
& $(0.832)$ \\
Contract Enforcement x Contract Intensity x Importer Concentration & 1.258 \\
& $(0.929)$
\end{tabular}

Contract Enforcement

Contract Enforcement Squared

Notes: Number of observations rounded for disclosure avoidance. Column 1 estimates specification (3.3). Contract intensity of an industry captures the proportion of inputs used in production that are neither bought or sold on an exchange nor referenced priced, obtained from Nunn (2007). Importer concentration is defined as in equation (3.4). Column (2) includes a square of contract enforcement as an additional variable to the baseline specification in equation (3.2). The following control variables are included in Column 1: log number of suppliers per produc t-country, log number of cities per product-country. The following control variables are included in Column 2: regulatory trade barrier index, internet per 100 people, percentage of paved roads, log GDP per capita (constant 2010 USD), log population, log land area common language indica tor, log gini lights, log number of suppliers per product-country, $\log$ number of cities per product-country. Standard errors clustered by country in parentheses. $*<0.10, * *$ $<0.05 ; * * *<0.01$ 
Figure 1. Spatial Concentration of Sourcing using EG Index, 2011

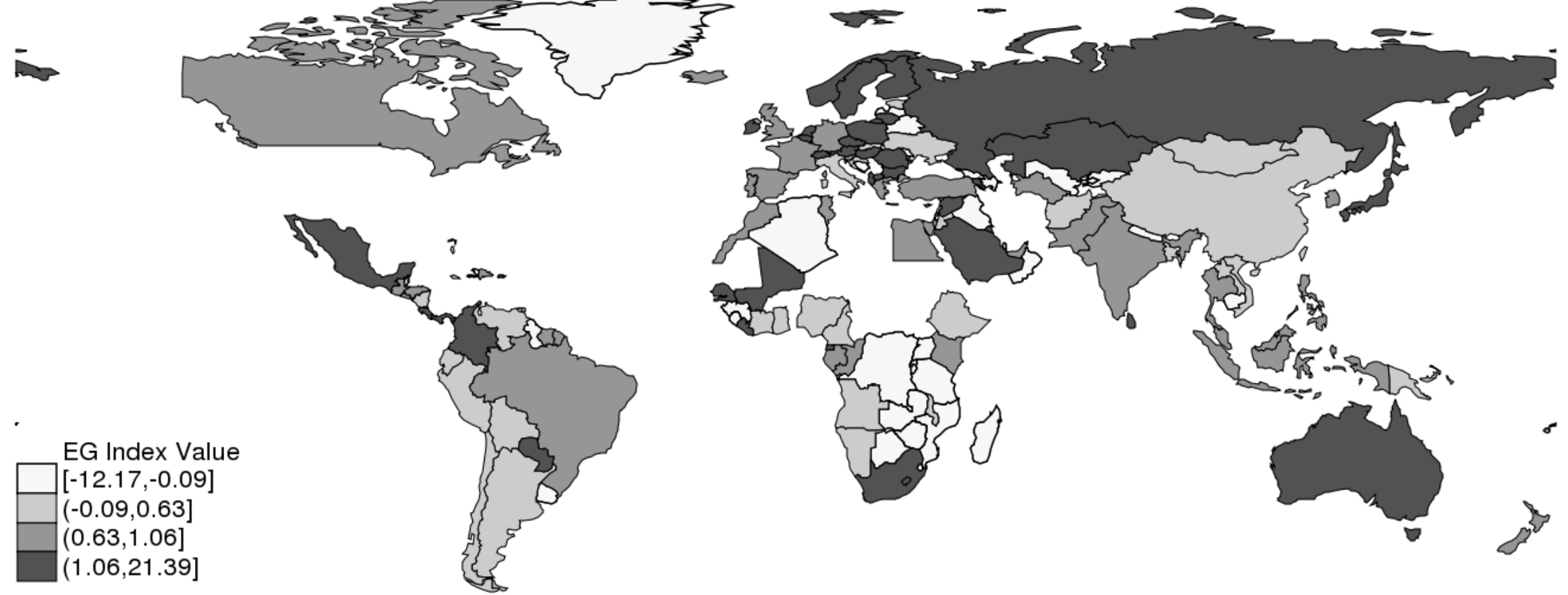

Notes: This figure displays the average EG index by country. Darker (lighter) shades of gray correspond to higher (lower) values of the index indicating greater (smaller) supplier concentration. Countries shaded in white fail to pass Census Bureau disdosure requirem ents. The U.S. is shaded white becau se it is the importing country. 
Figure 2. Spatial Concentration of Sourcing using EG Index by Institutional Quality, 2011

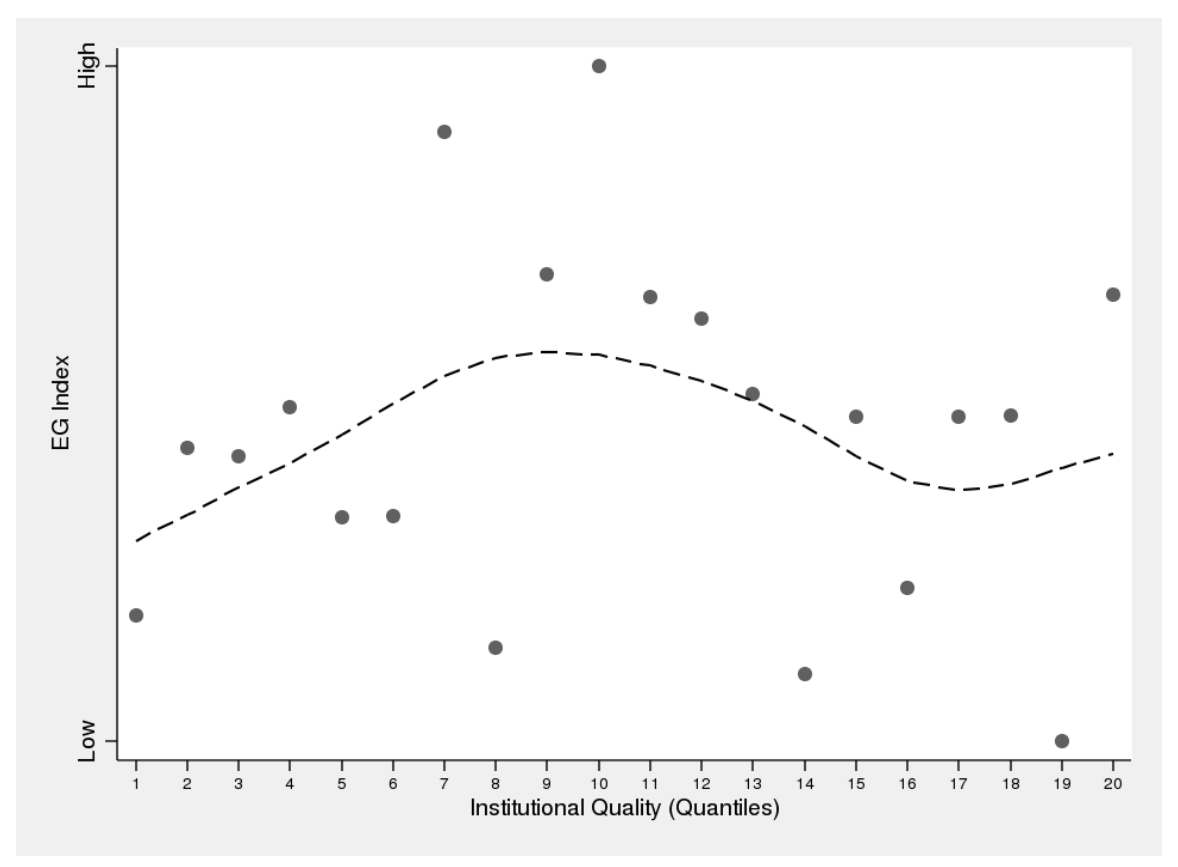

Notes: This figure displays the average EG index by quantiles of country-level institutional quality where quantile 1 denotes lowest and quantile 20 the highest institutional quality. The range of EG index values are displayed as "Low" to "High" for disclosure avoidance. The dashed line represents a locally weighted scatterplot smoothing (LOWESS) line of regressing the measure of supplier concentration on the quantiles of institutional quality. 


\section{Appendix}

Table A1. Country-level Determinants of Single-Supplier Status

\begin{tabular}{lc}
\hline Dependent Variable: Single-Supplier Status & $(1)$ \\
& OLS \\
\hline Contract Enforcement & -0.002 \\
& $(0.014)$ \\
Regulatory Trade Barrier & -0.014 \\
& $(0.021)$ \\
Internet per 100 people & -0.000 \\
& $(0.001)$ \\
\% Paved Roads & -0.001 \\
& $(0.001)$ \\
Log GDP Per Capita (constant 2010 USD) & -0.026 \\
& $(0.033)$ \\
Log Population & $-0.089^{* * *}$ \\
& $(0.016)$ \\
Log Land Area & $0.047^{* *}$ \\
& $(0.019)$ \\
Common Language & 0.049 \\
Fixed Effect & $(0.039)$ \\
Notes: Number of observations rounded for disclosure avoidance. Dependent variable is an indicator \\
that takes on a value of 1 if an importer sources a product from a single supplier in a given country \\
and 0 otherwise. Standard errors clustered by country in parentheses. $*<0.10, * *<0.05 ; * * * 0.01$. \\
\end{tabular}

Table A2. Firm Size Distribution by Single-Supplier Status, 2011

\begin{tabular}{ccc}
\hline Firm Size & Single-Supplier & Multi-Supplier \\
\hline Panel A: Share of Importers & & 39 \\
\hline Large $(500+)$ & 36 & 61 \\
Small $(<=500)$ & 64 & \\
\hline Panel B: Share of Value & & 96 \\
Large $(500+)$ & 95 & 4 \\
\hline Small $(<=500)$ & 5 &
\end{tabular}

Notes: This table displays the share of importers (in Panel A) and import value (in Panel B) represented by importers that source a product from a single supplier in a given country (single-supplier) and importers that source a product from multiple suppliers in a given country (multi-supplier) by two firm size classes: "large" employs more than 500 workers and "small" employs 500 or fewer workers. 
Table A3. Country- and Product-level Determinants of Importer Status

\begin{tabular}{|c|c|}
\hline Dependent Variable: Import & $\begin{array}{c}(1) \\
\text { OLS }\end{array}$ \\
\hline Product Complexity Index & $\begin{array}{c}-0.028^{* * *} \\
(0.002)\end{array}$ \\
\hline Contract Enforcement & $\begin{array}{c}0.011^{* * *} \\
(0.000)\end{array}$ \\
\hline Contract Enforcement Squared & $\begin{array}{c}-0.004^{* * *} \\
(0.000)\end{array}$ \\
\hline Regulatory Trade Barrier & $\begin{array}{c}0.003^{* * *} \\
(0.000)\end{array}$ \\
\hline Internet per 100 people & $\begin{array}{c}0.001^{* * *} \\
(0.000)\end{array}$ \\
\hline$\%$ Paved Roads & $\begin{array}{c}0.007^{* * *} \\
(0.000)\end{array}$ \\
\hline Log GDP Per Capita (constant 2010 USD) & $\begin{array}{c}0.006^{* * *} \\
(0.000)\end{array}$ \\
\hline Log Population & $\begin{array}{c}0.027^{* * *} \\
(0.000)\end{array}$ \\
\hline Log Land Area & $\begin{array}{c}-0.012^{* * *} \\
(0.000)\end{array}$ \\
\hline Common Language & $\begin{array}{c}-0.010^{* * *} \\
(0.000)\end{array}$ \\
\hline Log Gini Lights (2008) & $\begin{array}{c}0.084^{* * *} \\
(0.000)\end{array}$ \\
\hline $\begin{array}{l}\text { Observations } \\
\text { Fixed Effect }\end{array}$ & $\begin{array}{c}72,530,000 \\
\text { Importer } \\
\end{array}$ \\
\hline
\end{tabular}

Notes: Number of observations rounded for disclosure avoidance. Dependent variable is an indicator that takes on a value of 1 if an importer sources a product (HS4) from a country and 0 otherwise. Standard errors clustered by country in parentheses. ${ }^{* * *}<0.01$. 


\section{A4. Conceptual Framework}

Consider a U.S. importer sourcing an input variety from a supplier located in city $j$ of country $c$, looking to source a new input variety from country $c$. The importer has to decide if it wants to source this new variety from a supplier in the same city or an alternate city from $n+1$ cities in country $c$. For simplicity, we assume that there is a single supplier of each variety in each city of country c. Suppliers in each city $k$ draw their quality or productivity $S_{k c}$ from a Fréchet distribution with shape parameter $\alpha$, which is identical but independent across all cities of country $c . S_{k c}$ is also the gain from sourcing from a supplier in city $k$ in country $c$.

Suppose that there is a probability that new suppliers may default in delivering the input to the U.S. importer. To mitigate this risk, the importer must incur a cost that erodes the importer's gain from sourcing to $\tau\left(\lambda_{c}\right) S_{k c}$. We conceptualize $\tau\left(\lambda_{c}\right)$ as the portion of the gain that the importer can capture from city $k \neq j$ relative to city $j$. Hence, $\tau\left(\lambda_{c}\right)=1$ for city $j$ and $\tau\left(\lambda_{c}\right) \in(0,1)$ for $k \neq j$, because the existing supplier in $j$ is able to provide information to the importer on the reliability of the new supplier and/or sanction default. $\lambda_{c}$ measures institutional quality in country $c$ so that $\tau^{\prime}\left(\lambda_{c}\right)>0$. In other words, in environments of weaker institutional quality, the cost of mitigating risks is higher and the importer captures a smaller proportion of the gain from sourcing from a supplier in a new city.

Sourcing from a new city requires a fixed cost common across all cities $k \neq j, f_{c}$. These fixed costs include expansion costs like search costs for new suppliers and establishing transportation links in a new city. Then, for $S_{j c}=s_{j c}$ the likelihood $p_{j}$ that the U.S. importer sources from the supplier in city $j$ is given by

$$
\begin{gathered}
p_{j}=\prod_{k \neq j} P\left(\tau\left(\lambda_{c}\right) S_{k c}-f_{c}<s_{j c}\right)=\prod_{k \neq j} P\left(S_{k c}<\frac{s_{j c}+f_{c}}{\tau\left(\lambda_{c}\right)}\right) \\
=\exp \left(-n\left(\frac{s_{j c}+f_{c}}{\tau\left(\lambda_{c}\right)}\right)^{-\alpha}\right)
\end{gathered}
$$

Then,

$$
\frac{\delta p_{j}}{\delta \lambda_{c}}=\exp \left(-n\left(\frac{s_{j c}+f_{c}}{\tau\left(\lambda_{c}\right)}\right)^{-\alpha}\right)\left[n \alpha\left(\frac{s_{j c}+f_{c}}{\tau\left(\lambda_{c}\right)}\right)^{-\alpha-1}\right]\left[\frac{-\left(s_{j c}+f_{c}\right) \tau^{\prime}\left(\lambda_{c}\right)}{\tau\left(\lambda_{c}\right)^{2}}\right]<0
$$

In words, in institutionally weaker countries, the likelihood of sourcing the new shipment from the same city is higher, leading to concentration of sourcing. 